\title{
Feeding Patterns and Xenomonitoring of Trypanosomes among Tsetse Flies around the Gashaka-Gumti National Park in Nigeria
}

\author{
Solomon Ngutor Karshima, ${ }^{1}$ Idris A. Lawal, ${ }^{2}$ and Oluseyi Oluyinka Okubanjo ${ }^{2}$ \\ ${ }^{1}$ Department of Animal Health, Federal College of Animal Health and Production Technology, PMB 001, Vom, Nigeria \\ ${ }^{2}$ Department of Veterinary Parasitology and Entomology, Ahmadu Bello University, PMB 1045, Zaria, Nigeria \\ Correspondence should be addressed to Solomon Ngutor Karshima; torkarshima@yahoo.co.uk
}

Received 22 September 2015; Accepted 17 January 2016

Academic Editor: Bernard Marchand

Copyright (c) 2016 Solomon Ngutor Karshima et al. This is an open access article distributed under the Creative Commons Attribution License, which permits unrestricted use, distribution, and reproduction in any medium, provided the original work is properly cited.

\begin{abstract}
In order to understand the epidemiology of trypanosomoses in Gashaka-Gumti National Park, Nigeria, we determined the density, infection rates, and feeding patterns of tsetse flies using biconical traps, ITS, and mitochondrial cytochrome b PCRs. A total of 631 tsetse flies were captured, of which 531 (84.2\%) and 100 (15.8\%) were analyzed for trypanosomes and blood meals, respectively. Tsetse distribution varied significantly $(p<0.05)$ across study sites with average trap and daily catches of 4.39 and 26.34 , respectively. Overall tsetse infection rate was $5.08 \%$ and ranged between $3.03 \%$ and $6.84 \%$ across study sites. We identified 10 T. brucei, 3 T. congolense savannah, 2 T. congolense forest, and 2 mixed infections among the 13 pools made from the 27 flies positive for trypanosomes with light microscopy. The distribution of vertebrate blood meals in tsetse flies varied significantly $(p<0.05)$ and ranged between $6.0 \%$ and $45 \%$ across hosts. We also observed dual feeding patterns involving at least 2 hosts in $24 \%$ and multiple feeding involving at least 3 hosts in $17 \%$ of the flies. We observed predominance of G. palpalis which also recorded higher infection rate. T. brucei was more prevalent among tsetse flies. Tsetse flies fed predominantly on cattle and less frequently on humans and also showed mixed feeding habits.
\end{abstract}

\section{Introduction}

Tsetse flies are large biting and blood-feeding flies of great economic, veterinary, and medical importance, due to their ability to transmit African animal and human trypanosomoses. Tsetse-transmitted trypanosomoses occur in 38 subSaharan African countries with averages of 15,000 human cases and one million cattle deaths reported yearly, exposing over 70 million people and 160 million cattle to the risk of infection in the region [1]. These vectors are distributed over wide range of habitats covering about 10 million square kilometers of potential grazing and farming lands in subSaharan Africa [2].

Tsetse abundance and feeding behaviours determine the degree of vector-host contact and may have a serious impact on the risk of pathogen transmission. The degree of contacts between vectors and vertebrate hosts is an important determinant of their vectoral capacity and is determined by the vector feeding patterns on its hosts. As vectors of human and animal trypanosomoses, the epidemiology of these diseases is determined largely by their abundance, density, and feeding behaviours [3].

The importance of vector feeding patterns in the epidemiology of diseases has been recognized for quite a long time. However, majority of the traditional approaches used earlier were serologically based and included haemagglutination crystallization, agglutination reactions, passive haemagglutination test, immunohistochemical methods $[4,5]$, precipitin test $[6,7]$, and enzyme linked immunosorbent assay [8-10]. Despite the level of successes achieved by these traditional approaches, limitations ranging between high percentage of false positives, low sensitivity, species cross infectivity, the need for producing specific antibodies to several species, and the inability to discover unpredicted hosts were reported [11].

The development of molecular based techniques for the identification of vertebrate host blood meals provides more convenient approaches and has already been employed in the detection of host blood meals in several arthropod 
TABLE 1: Primer names and sequences for the amplification of mitochondrial cytochrome b in tsetse blood meals [16].

\begin{tabular}{lcccc}
\hline Host & Primer & Sequence 5 ${ }^{\prime}-3^{\prime}$ & $T_{m}$ & Amplicon size \\
\hline Human & Human741-F & GGCTTACTTCTCTTCATTCTCTCCT & 66.08 & 334 \\
Dog & Dog368F & GGAATTGTACTATTATTCGCAACCAT & 62.30 & 680 \\
Cattle & Cow121-F & CATCGGCACAAATTTAGTCG & 58.35 & 561 \\
Pig & Pig573-F & TTAGTCGCCTCGCAGCCGTA & 64.48 & 453 \\
Universal reverse & UNREV1025 & GGTTGTCCTCCAATTCATGTTA & 58.95 & - \\
\hline
\end{tabular}

vectors including tsetse flies [12], ticks $[13,14]$, triatomine bugs [15], and mosquitoes [16, 17]. In order to understand the epidemiology of trypanosomosis in the Gashaka-Gumti National Park in Nigeria, we trapped and studied the feeding patterns of tsetse flies using the mitochondrial cytochrome b PCR and xenomonitored trypanosomes in tsetse flies using ITS PCR.

\section{Materials and Methods}

2.1. Study Area. The study was carried out in Gashaka-Gumti National Park which is located in Taraba State, Northeastern Nigeria, between latitudes $6^{\circ} 55^{\prime}$ and $6^{\circ} 17^{\prime} \mathrm{N}$ and longitudes $11^{\circ} 13^{\prime}$ and $11^{\circ} 21^{\prime} \mathrm{E}$. It is the largest national park in Nigeria, covering $6402 \mathrm{~km}^{2}$ and consisting of both savannah grassland and montane forest vegetation. Altitude ranges from 457 meters $(1,499 \mathrm{ft})$ to 2419 meters $(7,936 \mathrm{ft})$. It is an important water catchment area for the Benue River with abundant river flow even during the markedly dry season. Enclaves for local Fulani pastoralists exist within the park's boundary allowing for farming and grazing. The reserve also contains a wide range of wild fauna of over 103 different species [18]. The major occupation of the inhabitant is agriculture.

2.2. Study Design. We conducted a cross-sectional study in four randomly selected villages (Burto, Gindin Dutse, Goje, and Serti) located at least 5-10 km apart around the Gashaka community taking cognisance of their relationship with the Gashaka-Gumti National Park which is a tourist centre. We identified forested and riverine areas where 6 traps were mounted 100 meters apart two times weekly for four months in each of the four villages.

2.3. Tsetse Trapping, Identification, and Dissection. Tsetse flies were trapped by the use of biconical traps as described by Charllier and Laveissiere [19]. Six traps were mounted 100 meters apart along streams twice every week between July and October, 2014. Traps were emptied every 24 hours and the flies were identified using morphological characteristics as described by Murray et al. [20]. Following identification, a proportion of the collected tsetse flies were dissected using dissection microscope to check for vector stages of trypanosomes on the field while the most engorged were selected for blood meal identification. Flies that were positive following dissection and the engorged were all preserved at $-80^{\circ} \mathrm{C}$ until needed for PCR.

2.4. DNA Extractions. Blood meal DNA extraction was done using the modified salt procedure earlier described by Norris et al. [21]. Tsetse abdomen was detached from the thorax and head and homogenized in $100 \mu \mathrm{L}$ of extraction buffer containing $0.1 \mathrm{M} \mathrm{NaCl}, 0.2 \mathrm{M}$ sucrose, 0.1 M Tris- $\mathrm{HCl}, 0.05 \mathrm{M}$ EDTA, pH 9.1, and 0.5\% sodium dodecyl sulfate (SDS) and incubated at $65^{\circ} \mathrm{C}$ for one hour. Extracted DNA was then stored at $-20^{\circ} \mathrm{C}$ until needed for polymerase chain reaction.

Trypanosome DNA was extracted using GeneJET genomic DNA extraction kit (Thermo Scientific, Germany). Midguts of positive tsetse flies were pooled together in twos and homogenized and $200 \mu \mathrm{L}$ of the homogenate was lysed by adding $400 \mu \mathrm{L}$ of lyses solution and $20 \mu \mathrm{L}$ of proteinase $\mathrm{K}$ as recommended by the manufacturer. Extracted DNA was stored at $-20^{\circ} \mathrm{C}$ until needed for PCR.

2.5. PCR Identification of Blood Meals. We conducted multiplex PCR with four forward primers and a universal reverse primer to identify mitochondrial cytochrome $b$ of vertebrate hosts in blood meals of tsetse flies (Table 1). Cycling conditions were as follows: denaturation at $98^{\circ} \mathrm{C}$ for 10 seconds to activate the phusion flash II DNA polymerase, followed by 36 cycles at $98^{\circ} \mathrm{C}$ for 1 second, annealing for 50 seconds at temperatures of $58.5^{\circ} \mathrm{C}, 59.5^{\circ} \mathrm{C}, 62.0^{\circ} \mathrm{C}$, and $62.5^{\circ} \mathrm{C}$ for cattle, $\mathrm{dog}$, pig, and human primers, respectively. Extension was at $72^{\circ} \mathrm{C}$ for 40 seconds and final extension at $72^{\circ} \mathrm{C}$ for 5 minutes according to the manufacturers' instructions. All amplified products were analyzed by electrophoresis in a $2 \%$ agarose gel and UV illumination after ethidium bromide staining.

2.6. PCR Identification of Trypanosomes. ITS-1 PCR was used to identify the species of trypanosomes in the tsetse flies using primer sets with the sequences $5^{\prime}$-CCGGAAGTTCACCGATATTG- $3^{\prime}$ (forward) and $5^{\prime}$-TTGCTGCGTTCTTCAACGAA-3 ${ }^{\prime}$ (reverse) designed by [22]. PCR conditions were as follows: an initial denaturation step for 10 seconds at $98^{\circ} \mathrm{C}$ to activate the phusion flash II DNA polymerase, four cycles of amplification with 1-second denaturation at $98^{\circ} \mathrm{C}$, 5-second hybridization at $58^{\circ} \mathrm{C}$, and 15 -second elongation steps at $72^{\circ} \mathrm{C}$; eight cycles of amplification with 1-second denaturation at $98^{\circ} \mathrm{C}, 5$-second hybridization at $56^{\circ} \mathrm{C}$, and 15 -second elongation steps at $72^{\circ} \mathrm{C} ; 23$ cycles of amplification with 1second denaturation at $98^{\circ} \mathrm{C}, 5$-second hybridization at $54^{\circ} \mathrm{C}$, and 15 -second elongation steps at $72^{\circ} \mathrm{C}$; and a final extension step of 5 minutes at $72^{\circ} \mathrm{C}$ as described by the manufacturer.

2.7. Data Analysis. Data collated were analyzed using GraphPad Prism 4.0. Infection rates were calculated by dividing the number of infected tsetse flies by the total number of flies we dissected and expressed as percentages. Average tsetse catch per day was determined by summing the daily catch 
TABLE 2: Tsetse density and light microscopy infection rates in relation to study sites.

\begin{tabular}{|c|c|c|c|c|c|c|}
\hline Study sites & Total catch & Average catch/trap & Average catch/day & Total dissected & Number infected & Infection rate $(\%)$ \\
\hline Burto & 142 & 0.99 & 5.94 & 117 & 8 & 6.84 \\
\hline Gindin Dutse & 111 & 0.78 & 4.68 & 86 & 4 & 4.65 \\
\hline Goje & 91 & 0.63 & 3.78 & 66 & 2 & 3.03 \\
\hline Serti & 287 & 1.99 & 11.94 & 262 & 13 & 4.96 \\
\hline Total & 631 & 4.39 & 26.34 & 531 & 27 & 5.08 \\
\hline
\end{tabular}

TABLE 3: Tsetse infection rates in relation to Trypanosoma species identified.

\begin{tabular}{|c|c|c|c|c|c|c|c|}
\hline Tsetse species & Total catch & Number dissected & Number infected & Number of pools & T. brucei (\%) & T. congolense (\%) & Mixed infections \\
\hline G. palpalis & $408(64.7)$ & $347(65.3)$ & $19(5.5)$ & 9 & $5(55.6)$ & $2(22.2)$ & $2(22.2)$ \\
\hline G. tachinoides & $223(35.3)$ & $184(34.7)$ & $8(4.3)$ & 4 & $3(75.0)$ & $1(25.0)$ & $0(0.0)$ \\
\hline Total & $631(100)$ & $531(100)$ & $27(5.1)$ & 13 & $8(61.5)$ & $3(23.1)$ & $2(15.4)$ \\
\hline$\chi^{2}$ & - & - & 0.3168 & - & 0.4424 & 0.0120 & 1.0510 \\
\hline$p$ value & - & - & 0.5735 & - & 0.5060 & 0.9126 & 0.3054 \\
\hline
\end{tabular}

TABLE 4: Distribution of Trypanosoma species in relation to study sites.

\begin{tabular}{lcccc}
\hline Study sites & Number of tsetse infected & Number of pools & T. brucei & T. congolense \\
\hline Burto & 8 & 4 & 3 & 1 \\
Gindin Dutse & 4 & 2 & 1 & 1 \\
Goje & 2 & 1 & 4 & 1 \\
Serti & 13 & $\mathbf{1 3}$ & $\mathbf{1 0}$ & $\mathbf{5}$ \\
Total & $\mathbf{2 7}$ & & \\
\hline
\end{tabular}

per week and dividing by the number of days traps were mounted for the week while average catch per trap was determined by summing daily catch and dividing by the number of traps. We employ the Chi square $\left(\chi^{2}\right)$ and Fishers exact test where appropriate to determine variations in infection rates and the distribution of Trypanosoma species. The Analysis of Variance (ANOVA) was also employed to determine variations in the distribution of mammalian blood in tsetse blood meals and values of $p<0.05$ were considered significant.

\section{Result}

A total of 631 tsetse flies were captured with average trap and daily catches of 4.39 and 26.34, respectively. We dissected $531(84.2 \%)$ of the flies to check for the vector stages of trypanosomes while the remaining $100(15.8 \%)$ were analyzed for vertebrate sources of tsetse blood meals. Overall tsetse infection rate was $5.08 \%$ while those in relation to study sites were $6.84 \%, 4.65 \%, 3.03 \%$, and $4.96 \%$ for Burto, Gindin Dutse (G/Dutse), Goje, and Serti, respectively (Table 2).

Of the 2 species of tsetse flies captured, 408 (64.7\%) were Glossina palpalis while $223(35.3 \%)$ were G. tachinoides. Tsetse infection rates of $5.5 \%(19 / 347)$ and $4.3 \%(8 / 184)$ were revealed by G. palpalis and G. tachinoides, respectively (Table 3). The 27 tsetse flies positive for trypanosomes using light microscopy were distributed into 12 pools of two flies each and a pool of three flies yielding 13 pools which were subjected to the ITS PCR. We identified Trypanosoma brucei in 10, Trypanosoma congolense savannah in 3 , and
Trypanosoma congolense forest in 2 of the pools. Two of the pools revealed mixed infections of Trypanosoma brucei and Trypanosoma congolense (Table 4).

Of the 100 engorged tsetse flies subjected to the mitochondrial cytochrome b PCR to identify sources of tsetse blood meals, 45, 17, 6, and 32 fed on cattle, dog, man, and pig, respectively (Table 5). In addition, $24 \%$ of the flies fed on at least 2 vertebrate hosts, $17 \%$ fed on at least 3 vertebrate hosts, and $1 \%, 5 \%, 22 \%$, and $31 \%$ of the flies fed on man, dog, pig, and cattle, respectively (Table 5). The distribution of dual feeding among the 24 tsetse flies that fed on at least 2 vertebrate hosts was $15 \%, 7 \%, 20 \%$, and $24 \%$ for flies that fed on cattle-dog, cattle-man, cattle-pig, and dog-pig, respectively. Of the 17 tsetse flies that fed on at least 3 vertebrate hosts, $27 \%, 5 \%$, and $2 \%$ fed on cattle-dog-pig, cattle-man-pig, and dog-man-pig, respectively (Figure 1).

\section{Discussion}

The species of tsetse flies we reported in our study were earlier reported in the same region by Karshima et al. [23] and in other parts of Nigeria [24, 25] and were among the first eleven species of tsetse flies reported in Nigeria [26]. Glossina palpalis was predominantly higher than G. tachinoides in line with earlier reports $[25,27,28]$. Glossina palpalis usually has preference for thick forested areas with high temperatures and humidity for efficient breeding. Considering the site we studied which has similar kind of vegetation we presume that the vegetation may be a reason for the predominance of this species of tsetse fly. 
TABLE 5: Distribution of mammalian blood in tsetse blood meals.

\begin{tabular}{lccccccc}
\hline Study sites & Number of tsetse analyzed & Cattle (\%) & Dog (\%) & Man (\%) & Pig (\%) & Dual feeding (\%) & Multiple feeding (\%) \\
\hline Burto & 25 & $13(52.0)$ & $6(24.0)$ & $0(0.0)$ & $6(24.0)$ & $6(24.0)$ & $7(28.0)$ \\
G/Dutse & 25 & $12(48.0)$ & $4(16.0)$ & $2(8.0)$ & $7(28.0)$ & $2(8.0)$ & $2(8.0)$ \\
Goje & 25 & $6(24.0)$ & $5(20.0)$ & $3(12.0)$ & $11(44.0)$ & $4(16.0)$ & $3(12.0)$ \\
Serti & 25 & $14(56.0)$ & $2(8.0)$ & $1(4.0)$ & $8(32.0)$ & $12(48.0)$ & $5(20.0)$ \\
Total & $\mathbf{1 0 0}$ & $\mathbf{4 5 ( 4 5 . 0 )}$ & $\mathbf{1 7 ( 1 7 . 0 )}$ & $\mathbf{6 ( 6 . 0 )}$ & $\mathbf{3 2 ( 3 2 . 0 )}$ & $\mathbf{2 4 ( 2 4 . 0 )}$ & $\mathbf{1 7 ( 1 7 . 0 )}$ \\
\hline
\end{tabular}

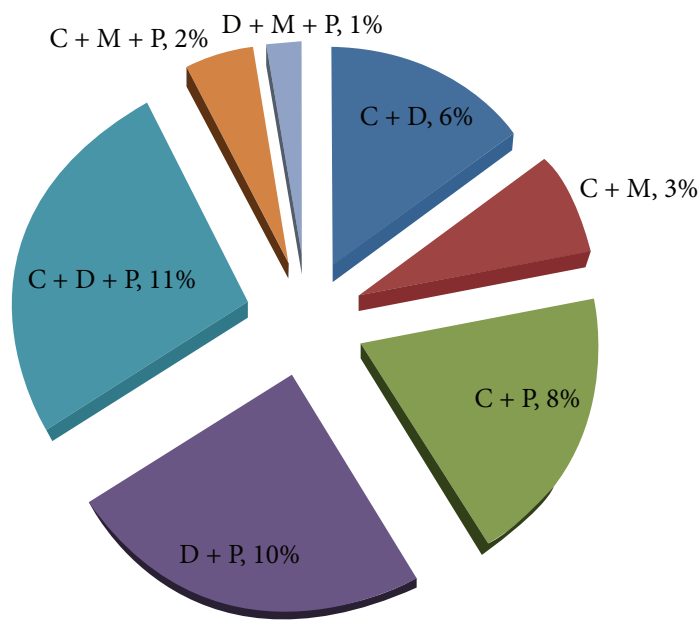

FIGURE 1: Distribution of mammalian blood in tsetse flies that fed on at least 2 hosts $[\mathrm{C}+\mathrm{D}$ (cattle and dog mixed blood), $\mathrm{C}+\mathrm{M}$ (cattle and man mixed blood), $\mathrm{C}+\mathrm{P}$ (cattle and pig mixed blood), $\mathrm{D}+\mathrm{P}$ (dog and pig mixed blood), $\mathrm{C}+\mathrm{D}+\mathrm{P}$ (cattle, dog, and pig mixed blood), $\mathrm{C}+\mathrm{M}+\mathrm{P}$ (cattle, man, and pig mixed blood), and $\mathrm{D}+\mathrm{M}+$ $\mathrm{P}$ (dog, man, and pig mixed blood)].

We observed an overall average daily tsetse catch per trap of 4.39 which falls within the range of 0.61-8.1 reported by other workers [29-31]. We expected a higher average daily catch considering the game reserve terrain in which we conducted our study and reports that confirm tsetse abundance during the rainy season [31]. We attributed our size of catch to the consecutive rainfall we observed during the trapping as tsetse activities are grossly reduced during rain and cold weather.

The location of Gashaka-Gumti National Park in Serti and its close proximity to Burto may explain the higher tsetse catch we recorded in these two areas considering the fact that the park may serve as suitable habitat for tsetse flies and provide sources of blood meals for these flies. This may also explain the higher infection rates in these two areas especially with the expected increased tsetse animal contact with over 103 wildlife species and livestock grazing in the area [18]. The mixed infections of T. brucei and T. congolense observed may be due to tsetse acquiring the infection from animals carrying the mixed infection in nature, from two different animal sources during feeding or even from the pools we made in our study.

Tsetse flies that were positive for trypanosomes by the use of light microscopy were pooled together before being subjected to PCR to increase the quantity of DNA in the samples and thus increase the chances of PCR detection. The 2 species of trypanosomes identified in tsetse flies are not reported for the first time in this region, suggesting that they are endemic. Of the Trypanosoma species identified T. brucei was most prevalent among tsetse flies indicating that they may be the commonest species infective to the domestic animals and wildlife species in the region as earlier documented [23, 32, 33]. Majority of trypanosome infections were observed among Glossina palpalis contrary to earlier reports by Desta et al. [31]. This variation may not be unconnected with factors such as differences in tsetse feeding frequencies, feeding patterns, and vectoral capacity.

The feeding pattern of tsetse vector is an important instrument in understanding the epidemiology of human and animal trypanosomoses [3]. In our study, we detached engorged tsetse abdomens from the thorax and head before PCR to reduce contamination of blood meal DNA by tsetse DNA. Selection of only engorged tsetse flies for the identification of host blood meals was to ensure the availability of host DNA in the blood meals since tsetse digestion of blood meals which usually occurs few days after ingestion may denature host DNA and impair its detection [16]. We also included only four species of vertebrate hosts in our assay because they were the commonest animals in the region where this work was conducted.

Tsetse feeding preference for cattle based on cattle size has been reported by Torr et al. [34]. Of all the vertebrate hosts included in our assay, cattle were the largest and this may explain why majority of the tsetse flies fed on them. The influence of host availability on tsetse feeding habits has also been documented [35]. This may also be a probable reason for the large proportion of pig blood identified by our study. Hunting dogs would have contributed to the number of tsetse flies that fed on dogs while activities like hunting, fishing, farming, and visit to rivers and streams would have exposed humans to the tsetse bites amounting to the number of tsetse that fed on humans.

Of particular concern are the dual and multiple feeding patterns involving more than one species of vertebrate hosts because this may be of great epidemiological importance in the area of spreading tsetse-borne infections between different vertebrate hosts including man in the region. Considering the proximity of this game reserve with the Fonten sleeping sickness focus of the Republic of Cameroon, there is the risk of trans-boundary tsetse flies acquiring Trypanosoma brucei gambiense and spreading the infection among humans and animal reservoirs in the region.

We concluded that Glossina palpalis is predominant and had higher infection rates. Trypanosoma brucei was more 
prevalent among tsetse flies. Tsetse flies fed predominantly on cattle and less frequently on humans and also showed mixed feeding habits. The risk of tsetse flies transmitting tsetseborne infection between humans and other vertebrate hosts exists in the region.

\section{Conflict of Interests}

There is no conflict of interests regarding the publication of this paper.

\section{References}

[1] OIE, "Standardized techniques for the diagnosis of tsetse transmitted trypanosomiasis," in OIE Terrestrial Manual, p. 49, OIE, Rome, Italy, 2008.

[2] F. A. S. Kuzoe, "Current situation of African trypanosomiasis," Acta Tropica, vol. 54, no. 3-4, pp. 153-162, 1993.

[3] E. Ducheyne, C. Mweempwa, C. De Pus et al., "The impact of habitat fragmentation on tsetse abundance on the plateau of eastern Zambia," Preventive Veterinary Medicine, vol. 91, no. 1, pp. 11-18, 2009.

[4] L. A. M. Gomes, R. Duarte, D. C. Lima, B. S. Diniz, M. L. Serrão, and N. Labarthe, "Comparison between precipitin and ELISA tests in the bloodmeal detection of Aedes aegypti (Linnaeus) and Aedes fluviatilis (Lutz) mosquitoes experimentally fed on feline, canine and human hosts," Memorias do Instituto Oswaldo Cruz, vol. 96, no. 5, pp. 693-695, 2001.

[5] J. M. Mwangangi, C. M. Mbogo, J. G. Nzovu, J. I. Githure, G. Yan, and J. C. Beier, "Blood-meal analysis for anopheline mosquitoes sampled along the Kenyan coast," Journal of the American Mosquito Control Association, vol. 19, no. 4, pp. 371375, 2003.

[6] M. M. D. S. Afonso, A. C. Gomes, C. R. V. Meneses, and E. F. Rangel, "Studies on the feeding habits of Lutzomyia (N.) intermedia (Diptera, Psychodidae), vector of cutaneous leishmaniasis in Brazil," Cadernos de Saúde Pública, vol. 21, no. 6, pp. 1816-1820, 2005.

[7] R. S. Fonteles, G. C. e Vasconcelos, P. C. B. Azevêdo et al., "Blood feeding preference of Lutzomyia whitmani (Diptera, Psychodidae) in a transmission area for American cutaneous leishmaniasis in the State of Maranhão, Brazil," Revista da Sociedade Brasileira de Medicina Tropical, vol. 42, no. 6, pp. 647650, 2009.

[8] E. Rossi, G. Bongiorno, E. Ciolli et al., "Seasonal phenology, host-blood feeding preferences and natural Leishmania infection of Phlebotomus perniciosus (Diptera, Psychodidae) in a high-endemic focus of canine leishmaniasis in Rome province, Italy," Acta Tropica, vol. 105, no. 2, pp. 158-165, 2008.

[9] M. M. dos Santos Afonso, R. Duarte, J. C. Miranda, L. Caranha, and E. F. Rangel, "Studies on the feeding habits of Lutzomyia (Lutzomyia) longipalpis (Lutz \& Neiva, 1912) (Diptera: Psychodidae: Phlebotominae) populations from endemic areas of American visceral leishmaniasis in North-eastern Brazil," Journal of Tropical Medicine, vol. 2012, Article ID 858657, 5 pages, 2012.

[10] A. M. Marassá, E. A. B. Galati, D. P. Bergamaschi, and C. A. Consales, "Blood feeding patterns of Nyssomyia intermedia and Nyssomyia neivai (Diptera, Psychodidae) in a cutaneous leishmaniasis endemic area of the Ribeira Valley, State of São
Paulo, Brazil," Revista da Sociedade Brasileira de Medicina Tropical, vol. 46, no. 5, pp. 547-554, 2013.

[11] K. G. da Silva Sales, P. L. Costa, R. C. S. de Morais et al., "Identification of phlebotomine sand fly blood meals by realtime PCR," Parasites \& Vectors, vol. 8, no. 1, article 230, 2015.

[12] S. Steuber, A. Abdel-Rady, and P.-H. Clausen, "PCR-RFLP analysis: a promising technique for host species identification of blood meals from tsetse flies (Diptera: Glossinidae)," Parasitology Research, vol. 97, no. 3, pp. 247-254, 2005.

[13] A. Estrada-Peña, J. J. Osácar, B. Pichon, and J. S. Gray, "Hosts and pathogen detection for immature stages of Ixodes ricinus (Acari: Ixodidae) in North-Central Spain," Experimental and Applied Acarology, vol. 37, no. 3-4, pp. 257-268, 2005.

[14] B. Pichon, D. Egan, M. Rogers, and J. Gray, "Detection and identification of pathogens and host DNA in unfed hostseeking Ixodes ricinus L. (Acari: Ixodidae)," Journal of Medical Entomology, vol. 40, no. 5, pp. 723-731, 2003.

[15] M.-F. Bosseno, L. S. García, F. Baunaure et al., "Short report: identification in triatomine vectors of feeding sources and Trypanosoma cruzi variants by heteroduplex assay and a multiplex miniexon polymerase chain reaction," American Journal of Tropical Medicine and Hygiene, vol. 74, no. 2, pp. 303-305, 2006.

[16] R. J. Kent and D. E. Norris, "Identification of mammalian blood meals in mosquitoes by a multiplexed polymerase chain reaction targeting cytochrome B," American Journal of Tropical Medicine and Hygiene, vol. 73, no. 2, pp. 336-342, 2005.

[17] R. J. Kent, M. Coetzee, S. Mharakurwa, and D. E. Norris, "Feeding and indoor resting behaviour of the mosquito Anopheles longipalpis in an area of hyperendemic malaria transmission in southern Zambia," Medical and Veterinary Entomology, vol. 20, no. 4, pp. 459-463, 2006.

[18] H. M. Chapman, S. M. Olson, and D. Trumm, "An assessment of changes in the montane forests of Taraba State, Nigeria, over the past 30 years," ORYX, vol. 38, no. 3, pp. 282-290, 2004.

[19] A. Charllier and C. Laveissiere, "A new trap for capturing Glossina (Diptera Muscidae): description and field trials," Cahiers de I'ORSTOM, Série Entomologie Médicale et Parasitologie, vol. 11, pp. 251-262, 1973.

[20] M. Murray, J. C. M. Trail, D. A. Turner, and Y. Wissocq, Livestock Productivity and Trypanotolerance. Network Training Manual, ILCA, Addis Abba, Ethiopia, 1983.

[21] D. E. Norris, A. C. Shurtleff, Y. T. Touré, and G. C. Lanzako, "Microsatellite DNA polymorphism and heterozygosity among field and laboratory populations of Anopheles gambiae s.s. (Diptera: Culicidae)," Journal of Medical Entomology, vol. 38, no. 2, pp. 336-340, 2001.

[22] Z. K. Njiru, C. C. Constantine, S. Guya et al., "The use of ITS1 rDNA PCR in detecting pathogenic African trypanosomes," Parasitology Research, vol. 95, no. 3, pp. 186-192, 2005.

[23] N. S. Karshima, I. Ajogi, G. Mohammed, and A. I. Lawal, "A survey for biting flies in three local government areas of Taraba State, Nigeria," Sokoto Journal of Veterinary Sciences, vol. 9, no. 1, pp. 36-38, 2011.

[24] A. B. Ahmed, "A peridomestic population of the tsetse fly Glossina palpalis palpalis Robineau-Desvoidy, 1830 (Diptera: Glossinidae) at Kontagora town, Niger state, Nigeria," Entomología y Vectores, vol. 11, no. 4, pp. 599-610, 2004.

[25] C. C. Ohaeri and M. C. Eluwa, "The population structure and physiological status of tsetse flies in Abia State, Nigeria," Journal of Animal and Veterinary Advances, vol. 6, no. 4, pp. 513-516, 2007. 
[26] D. A. T. Baldry, "Species list of the tsetse flies, genus Glossina (Diptera: Muscidae) in Nigeria," Nigerian Entomologists' Magazine, vol. 1, p. 44, 1967.

[27] R. Oluwafemi, "Prevalence and distribution of tsetse fly (mainly Glossina palpalis palpalis and Glossina tachinoides) in BICOT Project area in Lafia Local Government of Nassarawa State, Nigeria-implication for sustainable agricultural development," The Internet Journal of Parasitic Diseases, vol. 4, no. 1, pp. 1-3, 2008.

[28] V. P. Alibu, J. C. K. Enyaru, E. Matovu et al., "Molecular xenomonitoring of trypanosomes in tsetse flies," Journal of Parasitology and Vector Biology, vol. 7, no. 6, pp. 108-114, 2015.

[29] J. Bekele, K. Asmare, G. Abebe, G. Ayelet, and E. Gelaye, "Evaluation of Deltamethrin applications in the control of tsetse and trypanosomosis in the southern rift valley areas of Ethiopia," Veterinary Parasitology, vol. 168, no. 3-4, pp. 177-184, 2010.

[30] T. Ayele, D. Ephrem, K. Elias et al., "Prevalence of bovine trypanosomosis and its vector density in Daramallo District, South Western Ethiopia," Journal of Veterinary Advances, vol. 2, no. 6, pp. 266-272, 2012.

[31] M. Desta, S. Menkir, and A. Kebede, "The study on tsetse fly (Glossina species) and their role in the trypanosome infection rate in Birbir valley, Baro Akobo River system, western Ethiopia," Journal of Veterinary Medicine and Animal Health, vol. 5, no. 7, pp. 186-194, 2013.

[32] A. O. Majekodunmi, A. Fajinmi, C. Dongkum, K. Picozzi, M. V. Thrusfield, and S. C. Welburn, "A longitudinal survey of African animal trypanosomiasis in domestic cattle on the Jos Plateau, Nigeria: prevalence, distribution and risk factors," Parasites \& Vectors, vol. 6, no. 1, article 239, 2013.

[33] O. G. Fasanmi, U. P. Okoroafor, O. C. Nwufoh, O. M. BukolaOladele, and E. S. Ajibola, "Survey for Trypanosoma species in cattle from three farms in Iddo Local Government Area, Oyo State," Sokoto Journal of Veterinary Sciences, vol. 12, no. 1, pp. 57-61, 2014.

[34] S. J. Torr, A. Prior, P. J. Wilson, and S. Schofield, "Is there safety in numbers? The effect of cattle herding on biting risk from tsetse flies," Medical and Veterinary Entomology, vol. 21, no. 4, pp. 301311, 2007.

[35] L. F. Chaves, L. C. Harrington, C. L. Keogh, A. M. Nguyen, and U. D. Kitron, "Blood feeding patterns of mosquitoes: random or structured?” Frontiers in Zoology, vol. 7, article 3, 2010. 

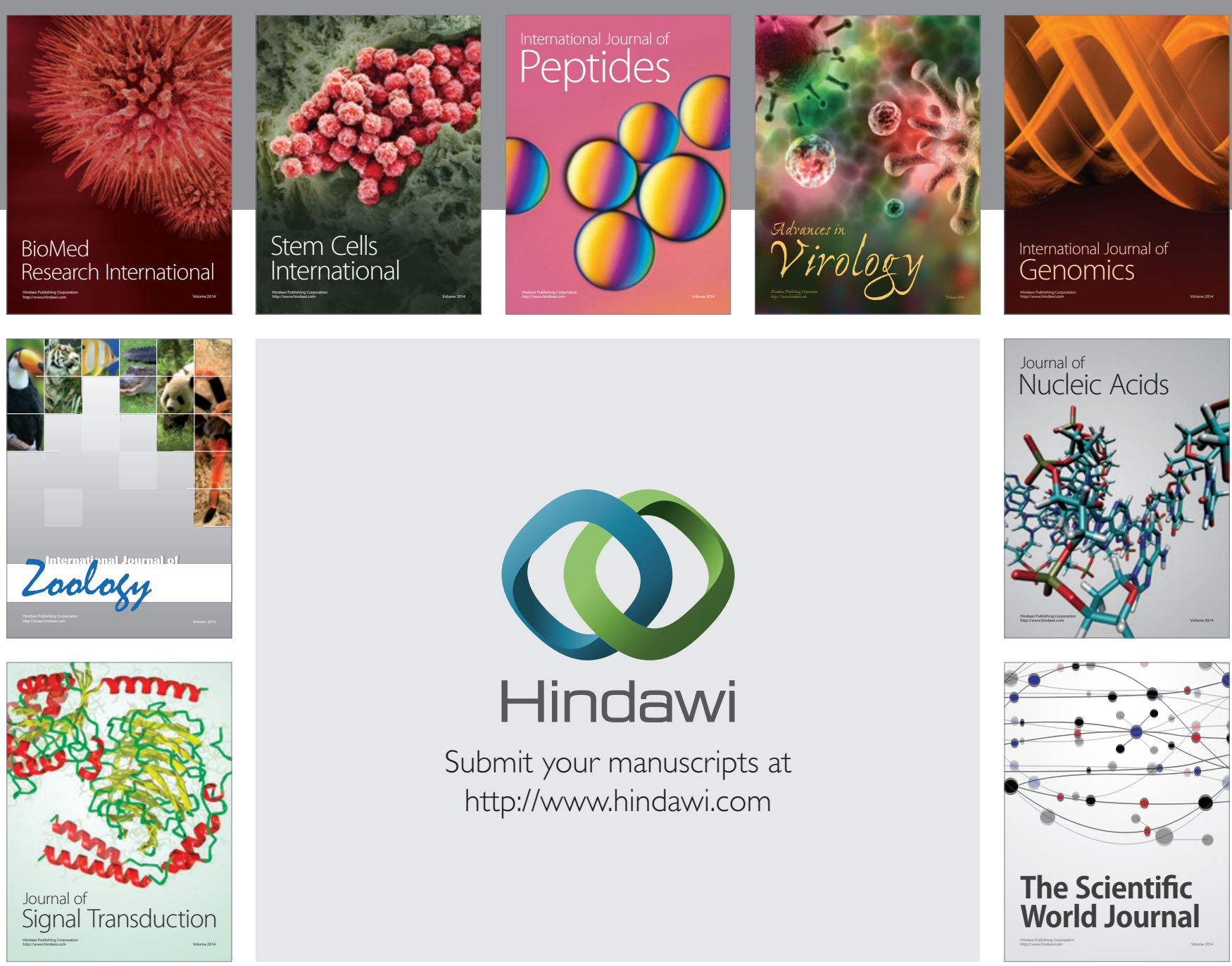

Submit your manuscripts at

http://www.hindawi.com
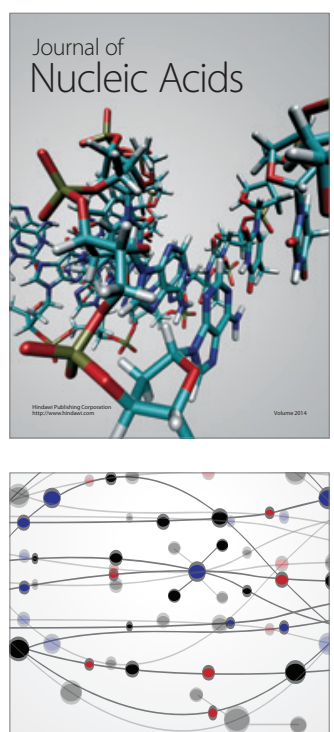

The Scientific World Journal
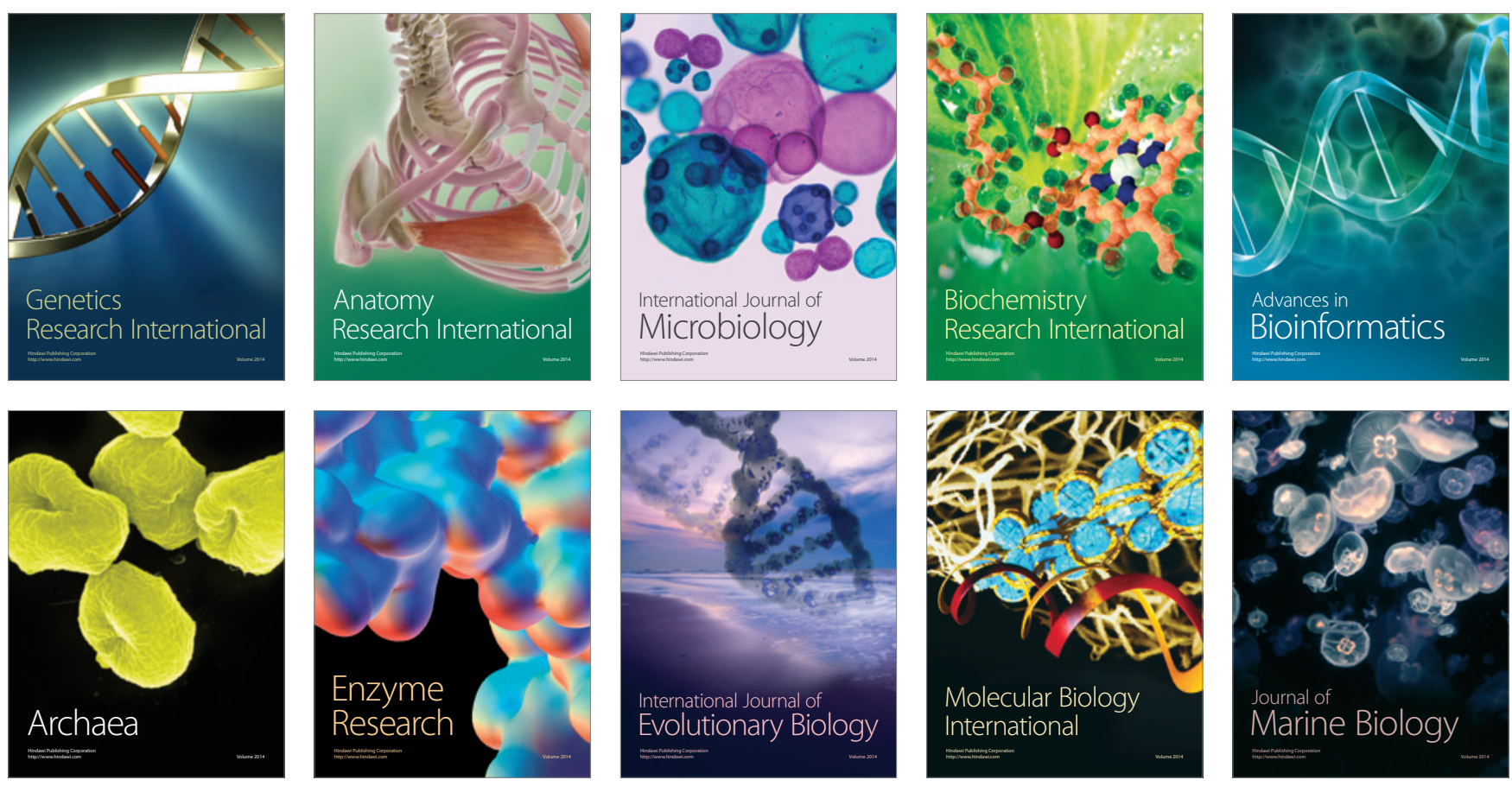